\title{
EL CONTROL DE CONVENCIONALIDAD EN SEDE de las Administraciones Públicas
}

\author{
CONVENTIONALITY CONTROL IN THE \\ Publics Administrations
}

\begin{abstract}
Pablo Ángel Gutiérrez Colantuono
Doctor en Derecho. Profesor argentino radicado en la Patagonia, donde es Director de la carrera de Posgrado en Derecho Administrativo en la Universidad Nacional del Comahue

(UNCO), y profesor adjunto por concurso, de la Carrera de Abogacia en la Facultad de Derecho y Ciencias Sociales (FADECS - UNCO) en la asignatura Derecho Administrativo. ORCID: [https://orcid.org/0000-0003-1464-052X]. drpablogutierrez@gmail.com
\end{abstract}

Recebido em: 06.03.2021 Aprovado em: 10.05 .2021 DO1: [https://doi.org/10.48143/rdai.18.pagc]

\section{ÁREAS Do DiREITo: Administrativo; Direitos Humanos; Internacional}

RESUMEN: El objetivo de este estudio es abordar el cambio en las relaciones administrativas $y$ jurídicas, lo que lleva a la necesidad de utilizar nuevas herramientas y crear nuevas categorias que se adapten a la evolución de la administracion pública. Sin duda, la dignidad humana debe ser el centro sobre el que se construya la discrecionalidad de la administración pública, com el fin de evitar arbitrad. La acción del Estado, por tanto, encuentra limites derivados de los derechos humanos, hecho que hace necesario que la administración pública obedezca no sólo a parámetros constitucionales, sino también a parámetros convencionales. En este sentido este trabajo buscará abrir una nueva perspectiva de conformación de acciones administrativas con control simultáneo de constitucionalidad y convencionalidad, estudiando la forma en que funcionan estas interrelaciones para encontrar los mejores resultados en las decisiones administrativas.
ABSTRACT: The purpose of this study is to deal with the changing in administrative and legal relationships, what leads to the need of using new tools and create new categories do adapt to the evolution of public administrations. Undoubtedly, the human dignity must be center on which the discretion of the public administration is built, in order to avoid arbitrations. The actions of the state, therefore, finds limits derived from the human rights, which makes necessary for the public administration to obey not only constitutional parameters, but also conventionaliy parameters. In this sense this work will seek to open a new perspective of conformation of administrative actions with simultaneos control of constitutionaliy and conventionality, studying the way how this interrelations works in order to find the best results in administrative decisions. 
Palabras clave: Evolución de las Administraciones Públicas - Dignidad humana - Discreción - Derechos humanos - Control de Constitucionalidad y Convencionalidad.
Kerwords: Evolution of Public Administrations Human Dignity - Discretion - Human rights Control of Constitutionaliy and Conventionality.

\begin{abstract}
SumÁRI0: 1. Introducción. 2. ¿Por qué ocuparnos de las Administraciones Públicas y la convencionalidad?. 3. Control de convencionalidad interno. 3.1. El control de convencionalidad interno es exteriorización del principio evolutivo de los derechos humanos. 3.2. El control de convencionalidad interno es un deber estatal y una garantia ciudadana. 3.3. El control de convencionalidad interno se encuentra matizado. 3.4. El control de convencionalidad interno es simétrico con el de constitucionalidad. 3.5. El control de convencionalidad es instrumental del efecto útil. 3.6. El control de convencionalidad interno posee una función pedagógica. 3.7. El control de convencionalidad interno aporta mayores niveles de legitimidad. 3.8. El control de convencionalidad interno es abierto y dinámico. 3.9. El control de convencionalidad interno es una herramienta que aplica el Derecho Internacional de los Derechos Humanos. 3.10. El control de convencionalidad interno es una herramienta de reciproca influencia. 4. Administraciones Públicas como sujetos obligados. 5. Control de convencionalidad en la sede de las propias Administraciones Públicas. 6. ¿Pueden las Administraciones Públicas declarar inconvencional v/o inaplicar una ley o reglamento en su propia sede?.
\end{abstract}

\title{
1. INTRODUCCIÓN
}

La constitucionalización del orden convencional y la convencionalidad del orden constitucional, junto a la globalización de los ordenamientos como proceso ya más integral ${ }^{1}$, genera sin dudas tensiones puertas adentro de los Estados.

1. Entre otros aspectos nos enseña Agustín Gordillo: "Cuando en 1962 definí al Derecho Administrativo excluyendo su calificación como derecho interno según era entonces habitual en la doctrina, como lo pueden ver en el Libro I del tomo 5, lo hice en base a fenómenos que ya se avizoraban en el horizonte. Con el tiempo han ido creciendo y multiplicándose los aspectos internacionales a cargo de organismos, tribunales judiciales o arbitrales externos" (GORDILLO, Agustín, "La corrupción como delito de lesa humanidad", Revista Jurídica de San Luís, Nro. 1, IJ-CCCXLIV-670, mayo 2017). Por otro lado, Alejandro Pérez Hualde ha explicado: "El Derecho Constitucional de estos tiempos nos muestra un Estado comprometido con políticas activas para hacer realmente vigentes los derechos fundamentales y estas políticas deben ser trazadas de un modo especialmente consensuado. "Las políticas públicas eficaces requieren de discusión y consenso (...) el derecho a la integridad personal no sólo implica que el Estado debe respetarlo (obligación negativa), sino que, además, requiere que el Estado adopte todas las medidas apropiadas para garantizarlo (obligación positiva), en cumplimiento de su deber general establecido en el art. 1.1 de la Convención 
Existe una alta presencia de las Administraciones Públicas y sus competencias, especialmente desde lo "normativo" en el concierto de la vida institucional y ciudadana. Es común en nuestros sistemas latinoamericanos observar una intensa potestad reglamentaria de las Administraciones Públicas. Cabe recordar que la discrecionalidad administrativa se expresa desde el límite que los derechos humanos imponen y dentro de estos el debido proceso se presenta como garantía propia, tanto de la decisión administrativa como de la judicial.

Es en este contexto, según explicaremos, que la construcción evolutiva de la Corte IDH en materia de tutela administrativa efectiva vino a atenuar los efectos de esta amplia presencia de las Administraciones Públicas, exigiendo que sean expresión de un estándar de derechos fundamentales determinado: la tutela administrativa efectiva.

\section{6. ¿Pueden las Administraciones Públicas declarar inconvencional y/O INAPLICAR UNA LEY O REGLAMENTO EN SU PROPIA SEDE?}

Es esperable brindar una repuesta positiva o negativa según respondamos la misma pregunta, pero en términos ya de control de constitucionalidad.

Podrá inaplicarse una norma por inconvencional si es posible inaplicarla por inconstitucional. Podrá declararse inconvencional una norma si esta es posible ser declarada inconstitucional en la propia sede de las Administraciones Públicas.

La inaplicabilidad, sea por razones de inconvencionalidad o por razones de inconstitucionalidad, no nos parece ser un tema complejo, es ello posible en el reparto constitucional argentino de división de poderes.

En cambio, la declaración de inconstitucionalidad e inconvencionalidad parece tener algún grado de mayor complejidad, justamente por la exclusiva y excluyente actividad de control que en este punto ejerce el poder judicial en un sistema judicialista ${ }^{24}$ como el argentino ${ }^{25}$. Por principio general le corresponde a

24. Desde el origen mismo del sistema constitucional Argentino este ha sido un principio básico de la división de poderes - art. 109 de la Constitución de la Nación Argentina -. Explica GELLI, María Angélica en su comentario a tal cláusula constitucional: "Por otro lado, la constitucionalidad de la jurisdicción administrativa aun con control judicial suficiente, es decir, con cabal revisión de los hechos y el derecho implicados encuentra en el art. 109 otra expresa limitación" (GELLI, María Angélica "Constitución de la Nación Argentina, Comentada y Concordada", LL, ed. 5 ampliada y actualizada, Bs. As., Argentina, 2018". pág. 535).

25. Cassagne ha explicado con claridad el tema: "En los países iberoamericanos ha prevalecido el sistema judicialista que confía a jueces encuadrados en la organización judicial el conocimiento de las causas contencioso administrativas, lo cual ha sido consagrado 
este y no a las Administraciones Públicas la declaración de inconstitucionalidad e inconvencionalidad, pero ello con algún matiz. En efecto, si se registran por fuera del poder judicial órganos que desarrollan materialmente actividad judicial, son estos entonces quienes también podrán, ejerciendo el debido control de convencionalidad, declarar inconvencional una norma.

Es en este contexto que ha de interpretarse aquello que la Corte IDH expresara en el Caso de "Personas Dominicanas y Haitianas Expulsadas vs. República Dominicana"26: "Finalmente, esta Corte considera pertinente recordar, sin perjuicio de lo ordenado, que en el ámbito de su competencia "todas las autoridades y órganos de un Estado Parte en la Convención tienen la obligación de ejercer un "control de convencionalidad." 27

El control de convencionalidad impacta en la actividad de las Administraciones Públicas porque ellas han de ajustar su comportamiento a la convencionalidad, principio de juridicidad amplio. El salto de legalidad a juridicidad de nuestras Administraciones Públicas impactó en la evolución del control judi$\mathrm{cial}^{28}$. Y ahora es el tiempo de un nuevo salto cualitativo en ese control tanto interno de las Administraciones Públicas como externo de orden materialmente judicial, propio del poder judicial y de otros órganos que despliegan tal actividad.

Ello así en tanto las Administraciones Públicas se encuentran atravesadas por el moderno constitucionalismo: aplicación, interpretación e impregnación constitucional al obrar de nuestras Administraciones Públicas.

Al ser simétrico lo constitucional con lo convencional, es claro que ese orden interno hoy está atravesado por el del orden de la convencionalidad. En efecto no

en normas de rango constitucional" (CASSAGNE, Juan Carlos, GONZALEZ PEREZ, Jesús "La Justicia Administrativa en Iberoamérica", Ed. Lexis Nexis Abeledo Perrot, Buenos Aires, Argentina, 2005, pág. 79).

26. Corte IDH, 28/08/2014, "Personas Dominicanas y Haitianas Expulsadas vs. República Dominicana".

27. Caso Corte IDH, 30/11/2012, "Masacre de Santo Domingo vs. Colombia s/ Sentencia de Excepciones Preliminares, Fondo y Reparaciones, párr.142, y Caso Corte IDH, 29/05/2014, "Norin Catrimán y otros (Dirigentes, miembros y activista del Pueblo Mapuche) vs. Chile", Fondo, Reparaciones y Costas, párr. 427.

28. "El sometimiento no solo a la ley sino al Derecho rebasa la mera relación del interés general con la legalidad. Es con todo el ordenamiento jurídico, encabezado por la Constitución y, por tanto, con los principios constitucionales y, por supuesto, con los principios generales del Derecho. El carácter pleno del sometimiento - con el que se refuerza el cometido servicial de la Administración - barre de un plumazo toda inmunidad de poder" - MEILÁN GIL, José Luís, "Intereses generales e interés púbico desde la perspectiva del derecho público español", Revista de Direito Administrativo \& Constitucional-A\&C, Nro. Especial 10 años, Ed. Fórum, Belo Horizonte, 2003, pág.178. 
puede aceptarse uno y rechazarse el otro, exigírsele a uno requisitos y efectos de su ejercicio diversos al otro. Se fortalecen y debilitan recíprocamente. El control de convencionalidad y el de constitucionalidad son conectores a nuestro criterio que permiten sostener la mirada sistémica en una multiplicidad de subsistemas.

De allí que nuestras Administraciones Públicas aplican, interpretan y son expresión de la impregnación de la convencionalidad. Ellas aplican el PSJCR e internalizan estándares de buena fe de manera consistente con los criterios expresados por los órganos y organismos que aplican e interpretan en el sistema internacional. La tarea de las Administraciones Públicas es constitucional y convencional. Aplica de oficio los parámetros de los derechos humanos ya que internamente su principio de oficialidad junto a la función tuitiva preventiva propia del PSJCR así lo indican.

Ello interpela a las Administraciones Públicas a adoptar distintas medidas dentro del margen de su propia competencia para lograr, en tiempo oportuno y de manera razonable, la adopción de medidas que: a) promuevan y protejan los derechos fundamentales $\mathrm{y} b$ ) prevengan posibles futuras responsabilidades internacionales.

\section{Pesouisas do Editorial}

\section{Veja também Doutrinas relacionadas ao tema}

- A ilegitimidade na imposição e no exercício do controle de convencionalidade pela Corte Interamericana de Direitos Humanos (CIDH), de João Pedro Kostin Felipe De Natividade e Débora Simões Da Silva - RPC 5/221-243 (DTR|2017|1620);

- Controle de convencionalidade nos Tratados de Direitos Humanos no ordenamento jurídico brasileiro, de Emerson Penha Malheiro e Aline Games Guaraldo da Silva - RT 1028/181-204 (DTR|2021|8618);

- Legislação brasileira sobre férias, convencionalidade e Covid-19: a parcial compatibilidade com a convenção 132 da OIT, de Bárbara Fagundes e Luciane Cardoso Barzotto - RDT 214/203-213 (DTR|2020|13284); e

- Pluralidade de ordens jurídicas e a interpretação das normas internacionais de Direitos Humanos, de Anna Catharina Machado Normanton e Ana Clara Toscano Aranha Pereira - RDCl 123/293-316 (DTR|2021|276). 
